\title{
A Diachronic Study of Diabetic Nephropathy in Two Autochthonous Lines of Rats to Understand Diabetic Chronic Complications
}

\author{
Juan Carlos Picena, Silvana Marisa Montenegro, Alberto Enrique \\ D’Ottavio, María Cristina Tarrés and Stella Maris Martínez \\ National University of Rosario \\ Argentina
}

\section{Introduction}

The worldwide epidemic of Type 2 Diabetes Mellitus, a result of recent deep changes in human lifestyle like sedentary and overly rich nutrition, has dramatic consequences in terms of morbidity, mortality and health care costs (Zimmet et al., 2001). Type 2 Diabetes Mellitus is a complex and multifactorial metabolic disorder which includes distinct nosological entities whose common patterns are hyperglycaemia, resistance to insulin and progressive chronic complications (American Diabetic Association, 2009).

A significant proportion of patients will develop a clinically relevant diabetic nephropathy with glomerulopathy, hyalinization of afferent and efferent arterioles, tubular and interstitial lesions (Fioretto et al., 2008). Nephropathy is a very serious complication in both Type 1 and Type 2 Diabetes Mellitus because patients with diabetic kidney disease are at a higher risk of mortality, mostly from cardiovascular complications, than diabetic patients without diabetic nephropathy (Dronavalli \& Barkis, 2008).

In the Western World the incidence of end-stage renal failure associated to the burden of diabetic nephropathy has increased in recent years and represents a failure of current disease control measure with serious public health implications (Stewart et al, 2006; Villar \& Zaoui, 2010). In Latin America, where incidence of Type 2 Diabetes Mellitus is on the rise and has reached epidemic proportions, people usually have poor disease control with the consequence of very high rates of diabetic nephropathy (Caballero \& Tenzer, 2007). A study performed in the Asian Pacific region has also shown that diabetic nephropathy was the most common cause of End-Stage Renal Disease in 9 of the 12 countries surveyed and 6 of the 12 countries had greater than $35 \%$ of their dialysis patients age 60 years and older (Lee, 2003). In United States, between $20 \%$ and $40 \%$ of patients ultimately develop diabetic nephropathy, the most common cause of End-Stage Renal Disease requiring dialysis (Dronavalli \& Barkis, 2008). Since 2000, the adjusted rate of prevalent End-Stage Renal Disease cases in the United States population ages 65-74, has increased $25 \%$ with an enormous economic impact on the healthcare systems (United States Renal Data System, 2010). In sum, worldwide incidence of diabetic nephropathy, a frequently silent and unrecognized disease, has increased about a 50\% between 1998 and 2008 and is now the leading cause of chronic kidney disease and End-Stage Renal Disease (Unites States Renal 
Data System, 2008). These epidemiological findings along with the several pathways which have been implicated in the progression of diabetic nephropathy, such as systemic and glomerular hypertension, metabolic derangements (hyperglycaemia, hyperlipidaemia, hyperinsulinaemia), and oxidative stress among others, indicate the complexity and the magnitude of diabetic nephropathy as a health concern.

Streptozotocin-induced pancreatic injury as well as uninephrectomy have been used for creating both rat and mouse models of Type 1 Diabetes Mellitus which develop renal injury with similarities to human diabetic nephropathy (Tesch \& Allen., 2007). Nephropathy is also a complication in rat models of spontaneous Type 2 Diabetes Mellitus as the obese Zucker (fatty) rat, the Goto Kakizaki rat (Janssen et al., 1999) and the hypertensive/NIH-corpulent rat (Nangaku et al., 2005) and in mice models as the BTBR Ob/Ob mutant mice (Hudkins et al., 2010). Either spontaneous or induced, rodent models of diabetes have been extensively used in diabetes research because of their usefulness for understanding the pathogenesis, the complications and the genetic or environmental influences that increase the risks of suffering Type 2 Diabetes Mellitus (Srinivasan \& Ramarao, 2007). These models, which depict many clinical features or related phenotypes of the disease, differ among them not only in its metabolic alterations but in their etiopathogenia (Breyer et al. 2005; Chatzigeorgiou et al., 2009). Although their use has allowed important advances toward the better understanding of human diabetic nephropathy, it has been recently pointed out that a lack of reliable animal models of diabetic complications still persists (Brosius et al., 2009).

The eSS rat is a spontaneously non-obese diabetic model obtained in Rosario, Argentina, by genetic manipulation, described in detail by Martinez et al. (1993). eSS rats evidence a progressive impaired glucose tolerance from 70 days of age onwards with hyperglycaemia and glycosuria worsening with ageing, being these signs much more striking in males (Martínez et al., 1988). Males exhibit insulin resistance and consequent insulin hypersecretion till 12 months of age but the hormone secretion decreases as diabetes progresses in the sequence of events from insulin resistance to overt diabetes (Martínez et al., 1988). This finding is coincident with conspicuous changes in the pancreas of 18 monthold eSS males, such as disruption of islet architecture and areas of pronounced fibrosis (Tarrés et al., 1992; Picena et al., 2007).

During the second year of life, eSS males are known to develop glomerulosclerosis and tubular nephrosis similar to those found in long-term human diabetes (Tarrés et al., 1992; Martínez et al., 1993). Older eSS males also develop bilateral cataracts but not retinopathy (Tarrés et al., 1990; Picena et al., 2005). Hence, the eSS rat was proposed as a model of noninsulin dependent diabetes characterized by complex glucose and lipid disorders (Martínez et al., 1993; Montanaro et al., 2003; Daniele et al., 2010).

eSMT rats (IIMe/Fm eSMT) derived from crossing eSS with $§$ rats, both parent strains belonging to the IIM stock (Calderari et al., 1991). \& (IIMb/Fm \&) is a line of moderately and spontaneous obese, fertile and hypertriglyceridemic rats (Calderari et al., 1987; Hisano et al., 1994). Upon crossing the F1 to obtain F2, the new colony eSMT was maintained as a closed one, where the full genetic history of each breeding rat is preserved (Tarrés et al., 2000). Young eSMT animals are more robust than eSS and develop higher levels of fasting hyperglycaemia, glycosuria, glucose intolerance, blood triglycerides and total cholesterol (Tarrés et al., 2000; Montenegro et al., 2005). eSMT males of 6 and 9 months show islets with altered shapes and fibrosis, as well as sporadic images of apoptosis and at 12 months of age, islets are reduced in number and size, resembling the histoarchitecture of eSS males during 
their second year of life (Tarrés et al., 2000). The sexual dimorphism is less evident in eSMT than in eSS diabetic syndrome (Picena, 2007).

The aim of this chapter is to present a wide and diachronic study of renal histopathology in eSS and eSMT rats, two strains which develop hereditary type 2 diabetic syndromes with different expression of the metabolic disorders, in order to characterize morphological changes. The arrival to conclusions could improve our knowledge and understanding of diabetic nephropathy.

\section{Material and methods}

The study was conducted in highly inbred 139 eSS (males $=71$; females $=68$ ) and 122 eSMT (males $=50$; females $=72$ ) rats from 3 to 26-30 months of age. Eumetabolic Wistar male rats of $12(n=15)$ and 21 month-old $(n=12)$ were used as controls.

Since the expected life span of the eSS and the eSMT rats in our laboratory ranges from 24-30 months, the morphological studies of diabetic nephropathy covered their entire life span. From 3 months of age onwards, groups of rats from eSS and eSMT strains were euthanized. Previously, glycaemia at $120 \mathrm{~min}$ after $10 \%$ glucose overload ( $200 \mathrm{mg} / 100 \mathrm{~g}$ body weight) via stomach tube was assessed. Blood samples were obtained by tail vein puncture. Plasma samples were analysed for glucose by the glucose oxidase enzymatic method using a commercial kit (Wiener Laboratories, Argentina).

Body and kidney weights were registered in every case. Sections of renal tissue were fixed in 10\% neutral-buffered formalin for 24 hours, embedded in paraffin, cut into sections of 4 $\mu \mathrm{m}$ thick, stained with hematoxylin-eosin (HE) and Periodic Acid-Schiff (PAS), and examined by light microscopy in a blinded fashion. In each histological specimen, capsular and glomerular diameters of 10 superficial and 10 juxtamedullary nephrons, cut at the vascular pole, were measured through a calibrated Shimadzu $®$ linear scale, placed in the eyepiece of a light microscopy. Correlations between age and body weights, and age and kidney weights were also performed.

Glomeruli were classified as small when the diameter was lower than $80 \mu \mathrm{m}$. Mesangial expansion, defined as the thickening mesangium by the deposit of an acidophilic, amorphous, PAS positive matrix substance and by the increase of cellular components, was considered diffuse when the glomerulus was wholly affected, and segmental if it was partially affected. Depending on its severity, it was graded as mild (ME +) or severe (SE ++$)$. Fifty glomeruli per kidney were randomly selected in each animal. Percentages (\%) of glomeruli displaying the same degree of injury (small glomeruli, $\mathrm{ME}+$ and $\mathrm{SE}++$ ) were obtained per animal. Correlations between age and percentage of small glomeruli, and age and mildly and severely affected glomeruli were calculated. Nodular increases in mesangial matrix as well as the presence of sclerotic or atubular glomeruli and capsular drop were also sought for. Tubulointerstitial and vascular injuries were considered on the basis of tubular dilation and atrophy, interstitial infiltration and fibrosis as well as of intimal thickening and arteriolar hyalinosis, respectively.

eSS rats were maintained in the breeding facilities of our School of Medicine, Rosario University, Rosario, Argentina. Wistar rats came from the animal breeding facilities in the School of Biochemical Science, Rosario University. Breeding conditions were the same for all the animals, including temperature regulation $\left(24^{\circ} \mathrm{C}\right)$ and light-darkness cycles as well as the artificial air exchange. In all the cases, the individuals had remained housed since they were 21 days old, in hanging collective cages. All animals were fed on a complete commercial 
diet, special for laboratory rats, and water was ad libitum. These experimental conditions were maintained until the animals were euthanized.

All data are reported as the mean \pm standard deviation. Statistical processing was partly carried out with the software SPSS 15, using the parametric and non-parametric methods referred below in the presentation of results.

All experimental procedures presented in this study were previously approved by the Bioethics Commission of School of Medicine, which assures adherence to the standards by the Guide for the Care and Use of Laboratory Animals.

\section{Results}

Body weights data in the experimental eSS and eSMT animals are seen in Table 1.

\begin{tabular}{|c|c|c|c|c|c|}
\hline \multirow{2}{*}{$\begin{array}{c}\text { Age } \\
\text { (months) }\end{array}$} & \multicolumn{2}{|c|}{ Line eSS } & \multicolumn{2}{|c|}{ Line eSMT } & \multirow{2}{*}{$\begin{array}{c}\text { Anova } \\
\text { (effect: p) }\end{array}$} \\
\hline & Males & Females & Males & Females & \\
\hline 3 & $\begin{array}{c}266 \pm 21 \\
(n=6)\end{array}$ & $\begin{array}{c}137 \pm 14 \\
(n=9)\end{array}$ & $\begin{array}{l}300 \pm 43 \\
(n=11)\end{array}$ & $\begin{array}{c}207 \pm 13 \\
(n=9)\end{array}$ & $\begin{array}{c}\text { Line:0.015 } \\
\text { Sex:0.000 } \\
\text { Interaction:0.000 }\end{array}$ \\
\hline 6 & $\begin{array}{c}342 \pm 26 \\
(n=19)\end{array}$ & $\begin{array}{c}245 \pm 43 \\
(n=7)\end{array}$ & $\begin{array}{c}368 \pm 55 \\
(n=5)\end{array}$ & $\begin{array}{c}284 \pm 31 \\
(n=11)\end{array}$ & $\begin{array}{c}\text { Line:0.016 } \\
\text { Sex:0.000 } \\
\text { Interaction:0.481 }\end{array}$ \\
\hline 9 & $\begin{array}{c}362 \pm 17 \\
(n=4)\end{array}$ & $\begin{array}{c}232 \pm 14 \\
(n=10\end{array}$ & $\begin{array}{l}397 \pm 61 \\
(n=12)\end{array}$ & $\begin{array}{c}308 \pm 40 \\
(n=6)\end{array}$ & $\begin{array}{c}\text { Line: } 0.004 \\
\text { Sex: } 0.000 \\
\text { Interaction: } 0.154\end{array}$ \\
\hline 12 & $\begin{array}{c}389 \pm 23 \\
(n=14)\end{array}$ & $\begin{array}{c}252 \pm 16 \\
(n=6)\end{array}$ & $\begin{array}{c}419 \pm 61 \\
(n=6)\end{array}$ & $\begin{array}{c}338 \pm 34 \\
(n=11)\end{array}$ & $\begin{array}{c}\text { Line:0.002 } \\
\text { Sex:0.000 } \\
\text { Interaction:0.215 }\end{array}$ \\
\hline 15 & $\begin{array}{c}399 \pm 72 \\
(n=9)\end{array}$ & $\begin{array}{c}337 \pm 15 \\
(n=6)\end{array}$ & $\begin{array}{c}431 \pm 91 \\
(n=5)\end{array}$ & $\begin{array}{c}370 \pm 42 \\
(n=7)\end{array}$ & $\begin{array}{c}\text { Line:0.051 } \\
\text { Sex:0.054 } \\
\text { Interaction:0.889 }\end{array}$ \\
\hline 18 & $\begin{array}{l}402 \pm 51 \\
(\mathrm{n}=14)\end{array}$ & $\begin{array}{c}345 \pm 36 \\
(n=12)\end{array}$ & $\begin{array}{r}416 \pm 47 \\
(\mathrm{n}=8)\end{array}$ & $\begin{array}{c}350 \pm 35 \\
(n=13)\end{array}$ & $\begin{array}{c}\text { Line:0.440 } \\
\text { Sex:0.000 } \\
\text { Interaction:0.031 }\end{array}$ \\
\hline 21 & $\begin{array}{c}357 \pm 40 \\
(\mathrm{n}=11)\end{array}$ & $\begin{array}{c}338 \pm 26 \\
(n=12)\end{array}$ & $\begin{array}{c}378 \pm 36 \\
(\mathrm{n}=8)\end{array}$ & $\begin{array}{c}348 \pm 58 \\
(n=12)\end{array}$ & $\begin{array}{c}\text { Line:0.063 } \\
\text { Sex:0.001 } \\
\text { Interaction:0.055 }\end{array}$ \\
\hline 24 & $\begin{array}{c}282 \pm 25 \\
(n=5)\end{array}$ & $\begin{array}{l}254 \pm 52 \\
(n=11)\end{array}$ & $\begin{array}{c}297 \pm 61 \\
(n=4)\end{array}$ & $\begin{array}{c}319 \pm 57 \\
(n=15)\end{array}$ & $\begin{array}{c}\text { Line:0.087 } \\
\text { Sex:0.099 } \\
\text { Interaction:0.034 }\end{array}$ \\
\hline$\geq 26$ & & $\begin{array}{c}242 \pm 26 \\
(\mathrm{n}=7)\end{array}$ & & $\begin{array}{c}313 \pm 37 \\
(\mathrm{n}=4)\end{array}$ & Line:0.001 \\
\hline
\end{tabular}

Values expressed as mean \pm standard deviation.

Table 1. Body weights (g) in male and female eSS and eSMT rats from 3 to $\geq 26$ months of age.

There was a significant line effect on body weight being eSMT heavier than eSS. A sexdependent effect was also demonstrated remaining the males heavier than the females. 
Table 1 also indicates that body weight increased in male and in female eSS rats till 18 months of age whilst eSMT rats underwent a similar evolution up to 15 months of age. Body weight was significantly correlated with age in both lines (eSS: $r=0.171 ; p=0.050$; eSMT: $r=0.218 ; p=0.016$ ). The low values obtained could be owed to the marked declination of body weight in the older animals.

As shown in Table 2, kidney weights increased up to 18 months of age in eSS males and till 15 months of age in eSMT males being always greater in eSMT rats than in eSS rats and in males than in females.

\begin{tabular}{|c|c|c|c|c|c|}
\hline \multirow{2}{*}{$\begin{array}{c}\text { Age } \\
\text { (months) }\end{array}$} & \multicolumn{2}{|c|}{ Line eSS } & \multicolumn{2}{|c|}{ Line eSMT } & \multirow{2}{*}{$\begin{array}{c}\text { Anova } \\
\text { (effect: } p \text { ) }\end{array}$} \\
\hline & Males & Females & Males & Females & \\
\hline 3 & $2.30 \pm 027$ & $1.25 \pm 0.25$ & $2.40 \pm 0.22$ & $1.94 \pm 0.24$ & $\begin{array}{c}\text { Line:0.005 } \\
\text { Sex:0.000 } \\
\text { Interaction:0.050 }\end{array}$ \\
\hline 6 & $2.79 \pm 0.32$ & $2.03 \pm 0.15$ & $2.84 \pm 0.45$ & $2.40 \pm 0.19$ & $\begin{array}{c}\text { Line:0.007 } \\
\text { Sex::0.000 } \\
\text { Interaction:0.022 }\end{array}$ \\
\hline 9 & $3.55 \pm 0.38$ & $2.26 \pm 0.16$ & $3.70 \pm 0.31$ & $2.55 \pm 0.38$ & $\begin{array}{c}\text { Line:0.041 } \\
\text { Sex:0.000 } \\
\text { Interaction:0.041 }\end{array}$ \\
\hline 12 & $3.15 \pm 0.63$ & $2.63 \pm 0.10$ & $4.02 \pm 0.94$ & $2.97 \pm 0.29$ & $\begin{array}{c}\text { Line: } 0.004 \\
\text { Sex: } 0.000 \\
\text { Interaction:0.001 }\end{array}$ \\
\hline 15 & $3.85 \pm 0.52$ & $2.75 \pm 0.26$ & $4.68 \pm 0.36$ & $3.22 \pm 0.28$ & $\begin{array}{c}\text { Line:0.952 } \\
\text { Sex:0.000 } \\
\text { Interaction:0.027 }\end{array}$ \\
\hline 18 & $4.06 \pm 0.57$ & $2.87 \pm 0.45$ & $4.39 \pm 0.55$ & $3.20 \pm 0.44$ & $\begin{array}{c}\text { Line:0.000 } \\
\text { Sex:0.000 } \\
\text { Interaction:0.026 }\end{array}$ \\
\hline 21 & $3.68 \pm 1.14$ & $2.82 \pm 0.35$ & $3.99 \pm 0.49$ & $3.17 \pm 0.21$ & $\begin{array}{c}\text { Line:0.546 } \\
\text { Sex:0.014 } \\
\text { Interaction:0.221 }\end{array}$ \\
\hline 24 & $3.21 \pm 1.13$ & $2.78 \pm 0.43$ & $3.88 \pm 0.46$ & $3.12 \pm 0.37$ & $\begin{array}{c}\text { Line:0.546 } \\
\text { Sex:0.014 } \\
\text { Interaction:0.032 }\end{array}$ \\
\hline$\geq 26$ & & $2.67 \pm 0.27$ & & $3.01 \pm 0.10$ & Line:0.001 \\
\hline
\end{tabular}

Values expressed as mean \pm standard deviation

Table 2. Kidney weights (g) in male and female eSS and eSMT rats from 3 to $\geq 26$ months of age

Direct and significant correlations were demonstrated between kidney weight and age in eSS and eSMT lines (eSS: $r=0.324 ; \mathrm{p}=0.000 ; \mathrm{eSMT}$ : $\mathrm{r}=0.498 ; \mathrm{p}=0.000$ ).

Line and sex effects were shown on glucose tolerance being glycaemia after $120 \mathrm{~min}$ glucose overload (G120) higher in eSMT rats than in eSS rats and in males than in females. A noticeable worsening of G120 with ageing was also evident (Table 3). eSS males reached the G120 threshold for diagnosis of overt diabetes (G120 $200 \mathrm{mg} / \mathrm{dl})$ from 6 months of age 
onwards and eSMT males, from 3 months of age. Females displayed similar values later (eSS from 12 months of age and eSMT from $9 \mathrm{~m}$ months of age). Wistar rats did not show any significant age-dependent changes remaining normoglycemic until 21 months of age (G120: $109 \pm 10 \mathrm{mg} / \mathrm{dl})$.

\begin{tabular}{|c|c|c|c|c|c|}
\hline \multirow{2}{*}{$\begin{array}{c}\text { Age } \\
\text { (months) }\end{array}$} & \multicolumn{2}{|c|}{ Line eSS } & \multicolumn{2}{|c|}{ Line eSMT } & \multirow{2}{*}{$\begin{array}{c}\text { Anova } \\
\text { (effect: p) }\end{array}$} \\
\hline & Males & Females & Males & Females & \\
\hline 3 & $168 \pm 37$ & $124 \pm 08$ & $201 \pm 75$ & $132 \pm 20$ & $\begin{array}{c}\text { Line:0.000 } \\
\text { Sex:0.012 } \\
\text { Interaction: } 0.330\end{array}$ \\
\hline 6 & $237 \pm 44$ & $179 \pm 39$ & $264 \pm 41$ & $187 \pm 28$ & $\begin{array}{c}\text { Line: } 0.018 \\
\text { Sex:0.034 } \\
\text { Interaction: } 0.342\end{array}$ \\
\hline 9 & $254 \pm 43$ & $188 \pm 27$ & $303 \pm 34$ & $207 \pm 35$ & $\begin{array}{c}\text { Line:0.016 } \\
\text { Sex:0.002 } \\
\text { Interaction: } 0.431\end{array}$ \\
\hline 12 & $299 \pm 64$ & $201 \pm 32$ & $324 \pm 43$ & $223 \pm 42$ & $\begin{array}{c}\text { Line:0.004 } \\
\text { Sex:0.000 } \\
\text { Interaction: } 0.154\end{array}$ \\
\hline 15 & $301 \pm 55$ & $222 \pm 25$ & $356 \pm 44$ & $270 \pm 33$ & $\begin{array}{c}\text { Line:0.051 } \\
\text { Sex:0.054 } \\
\text { Interaction:0.889 }\end{array}$ \\
\hline 18 & $309 \pm 49$ & $226 \pm 46$ & $429 \pm 27$ & $289 \pm 26$ & $\begin{array}{c}\text { Line: } 0.044 \\
\text { Sex:0.000 } \\
\text { Interaction: } 0.330\end{array}$ \\
\hline 21 & $314 \pm 42$ & $235 \pm 38$ & $433 \pm 52$ & $299 \pm 35$ & $\begin{array}{c}\text { Line:0.063 } \\
\text { Sex:0.001 } \\
\text { Interaction:0.752 }\end{array}$ \\
\hline 24 & $317 \pm 35$ & $240 \pm 32$ & $438 \pm 64$ & $301 \pm 27$ & $\begin{array}{c}\text { Line:0.028 } \\
\text { Sex:0.029 } \\
\text { Interaction:0.349 }\end{array}$ \\
\hline$\geq 26$ & & $242 \pm 22$ & & $309 \pm 46$ & Line:0.001 \\
\hline
\end{tabular}

Values expressed as mean \pm standard deviation

Table 3. Glycaemia after $120 \mathrm{~min}$ glucose overload $(\mathrm{mg} / \mathrm{dl})$ in male and female eSS and eSMT rats from 3 to $\geq 26$ months of age.

Present results indicate that at 3 month of age, when animals are still quite normoglycemic with the exception of eSMT males, kidneys did not show lesions visible under the light microscope and that renal injury became apparent from 6-month-old onward. The most frequent glomerular lesions were $\mathrm{ME}+$ and $\mathrm{SE}++$ diffuse mesangial expansion. Direct and significant correlations were evidenced between the percentage of diffuse mesangial expansion and the age (ME+: eSS $\rho=0.873 ; p=0.000$. eSMT $\rho=0.689 ; p=0.000$ and ME ++ : eSS $\rho=0.832 ; p=0.000$. eSMT $\rho=0.863 ; p=0.000)$. Nevertheless, an increasing number of small glomeruli $(>80 \mu \mathrm{m})$ were also verified in ageing eSS and eSMT individuals (eSS $\rho=$ 0.774; $\mathrm{p}=0.000$; eSMT $\rho=0.641 ; \mathrm{p}=0.000)$. In 12 month-old eSS rats, the glomerular diameter was higher in females ( $\delta$ : $110 \pm 8 \mu \mathrm{m}$ vs. + : $120 \pm 6$; p<0.01) whilst in eSMT strain these 
values were not different between sexes ( $\sigma^{\wedge}: 102 \pm 9 \mu \mathrm{m}$ vs. $\left.0: 106 \pm 11 ; \mathrm{p}>0.05\right)$. eSMT females showed similar values of glomerular diameter to those registered in eSS males (eSS $\delta: 110 \pm$ $8 \mu \mathrm{m}$ eSMT vs. eSMT + : $106 \pm 11 ; \mathrm{p}>0.05)$. Significant correlations between the percentages of small glomeruli, glomeruli with $\mathrm{ME}+$ and with $\mathrm{SE}++$ and age are shown in Figure 1.

ess

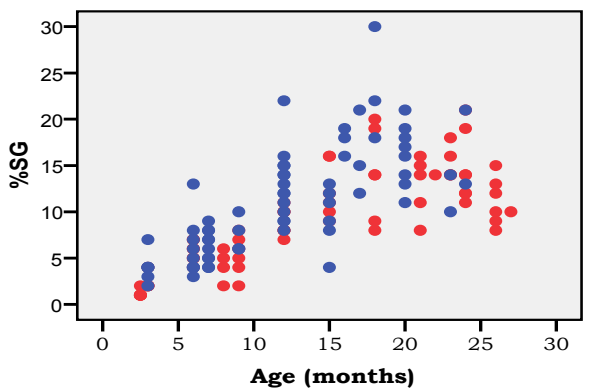

ess

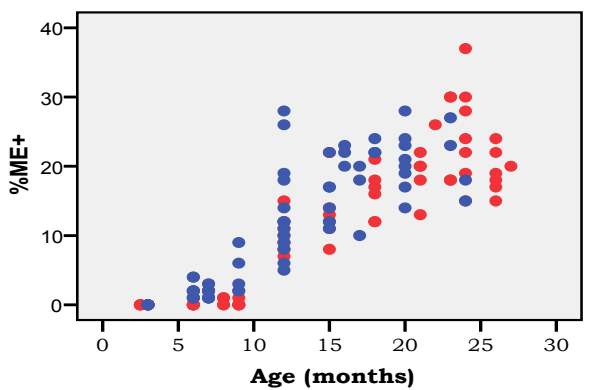

esS

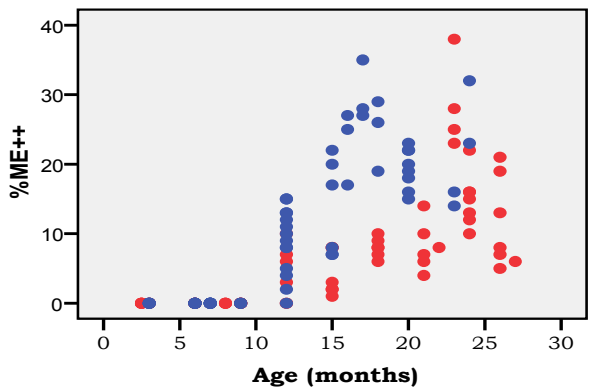

eSMT

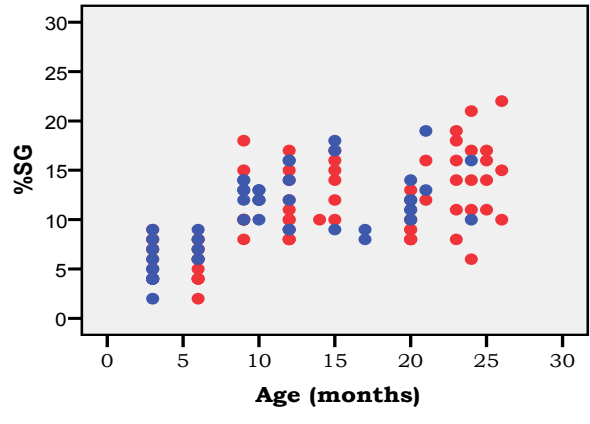

eSMT

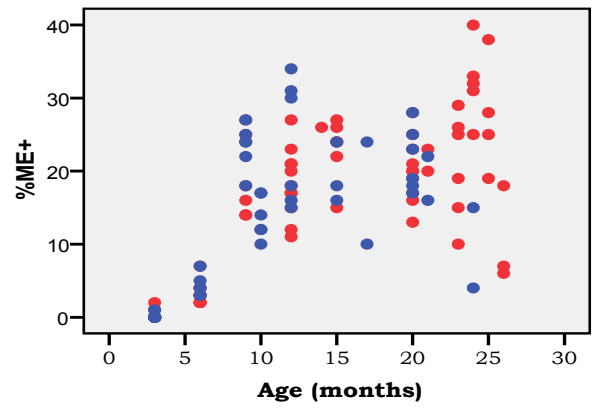

eSMT

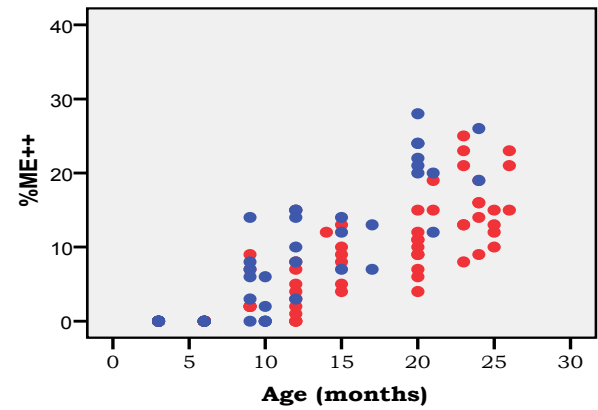

Fig. 1. Correlations between age and percentage of small glomeruli (eSS $\rho=0.774 ; p=0.000$; $\operatorname{eSMT} \rho=0.641 ; p=0.000), \operatorname{ME}+(\operatorname{eSS} \rho=0.873 ; p=0.000$. eSMT $\rho=0.689 ; p=0.000)$, and ME++ $(\mathrm{eSS} \rho=0.832 ; \mathrm{p}=0.000$. eSMT $\rho=0.863 ; \mathrm{p}=0.000)$ in male $(\bullet)$ and female $(\bullet)$ eSS and eSMT rats. 
In both lines, glomerular damage began with thickening of the basement membrane in the peripheral sector of the glomeruli, followed by segmentary or diffuse mesangial expansion due to the deposit of an acidophilic, amorphous, PAS-positive substance in addition to increased cellularity (Fig 2 A and 2 B). Progressively, eSMT y eSS males showed a rising number of small glomeruli (Fig $2 \mathrm{C}$ ). While glomerular histology by light microscopy was rather normal in eSS rats younger than 12 months of age, a mild PAS positive thickening of glomerular basement membrane was commonly detected in older males. Mild or severe mesangial expansion was usual in 21 month-old eSS males as well as basement membrane thickening. In eSMT rats, mild thickening of the basement membrane was detected from 6 month-old males onwards, and worsened in older animals.
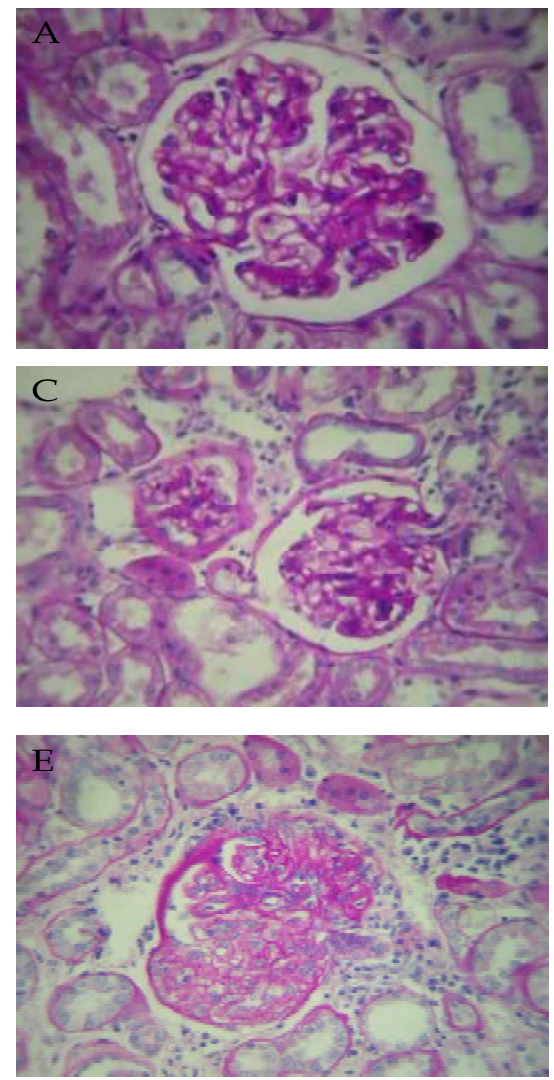
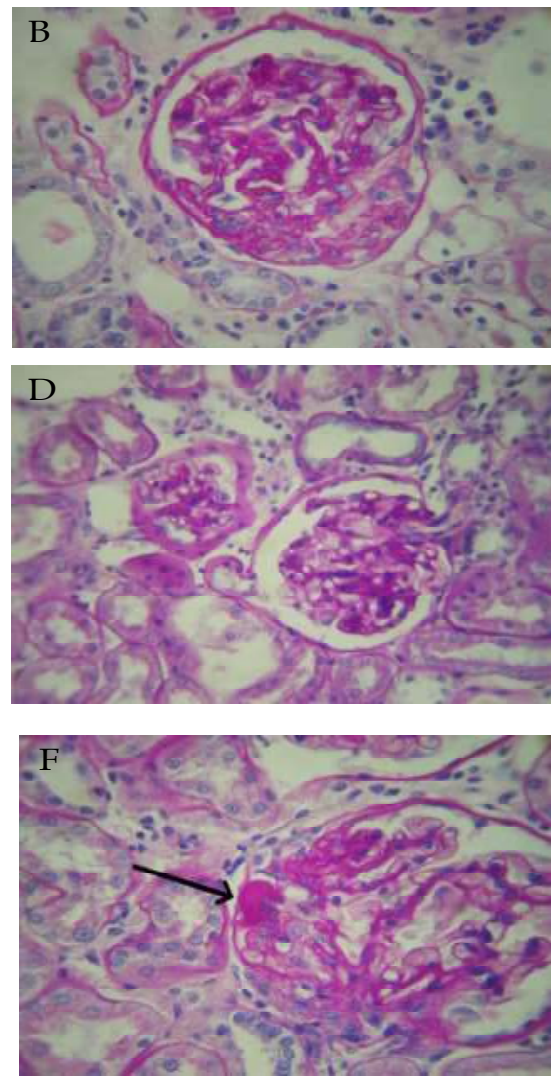

Fig. 2. (A) Mild diffuse mesangial thickening of the glomerular basement membrane (6-monthold eSMT male); (B) Segmentary mesangial expansion with an eccentric area of tuft-to-capsule adhesion (18-month-old eSMT male); (C) Left: small glomerulus (18-month-old eSS male); (D) Glomerulus totally occluded by fibrohyalinosis (21-month-old eSMT male); (E) Glomerulus with severe mesangial expansion and areas of tuft-to-capsule adhesion. Lymphocytic infiltrates near the vascular pole and intertubular interstitium. Atrophic tubules are also observed (24-month-old eSMT male); (F) Arrow: Kimmelstiel-Wilson-like nodular lesion (18month-old eSMT male). HE and Periodic acid-Schiff (PAS) stain. 300X, except F (400X). 
Prominent diffuse or segmentary mesangial expansion and, occasionally, areas of tuft-tocapsule adhesion were evident in the 12- and 18-month-old eSMT males. Severe injury was evidenced by many sclerotic glomeruli totally occluded (Fig 2 D) and a smaller number of atubular glomeruli with tuft adhesions in the older eSMT males (Fig 2 E). Prominent thickening of the peripheral glomerular basement membrane resulted in lobules with an abnormal architecture and a noticeable image of stiffness was observed in $60 \%$ of the eSMT rats and in $40 \%$ of the eSS after 21 months of age. Glomeruli with capsular drops or fibrin cap were not observed either in eSS or eSMT rats. A Kimmelstiel-Wilson-like nodular lesion was detected only in a 18-month-old eSMT male (Fig 2 F). Sporadically, periglomerular fibrosis was observed in eSMT and eSS females.
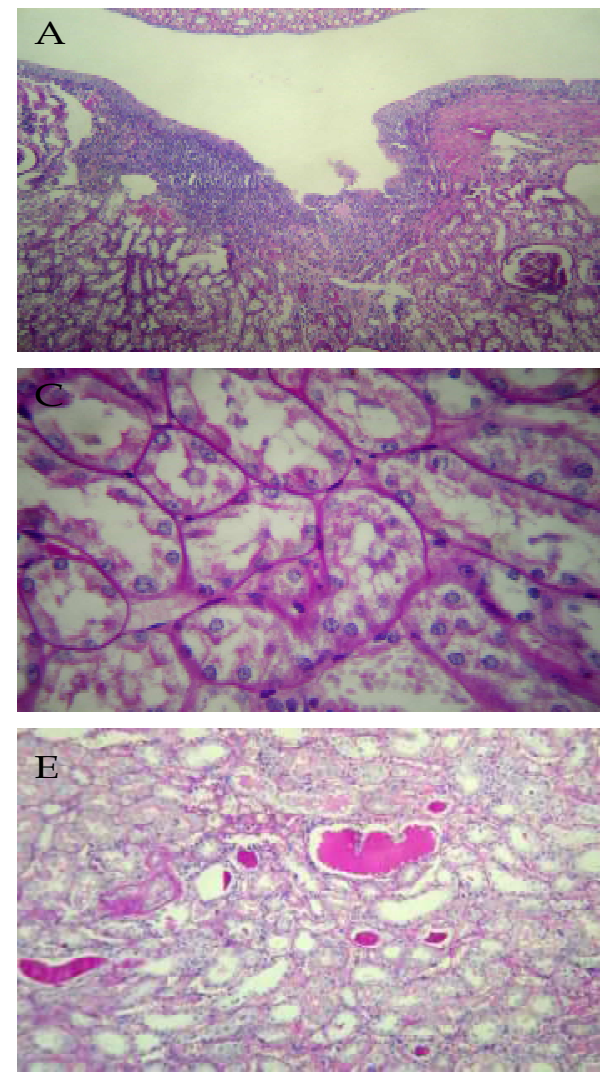
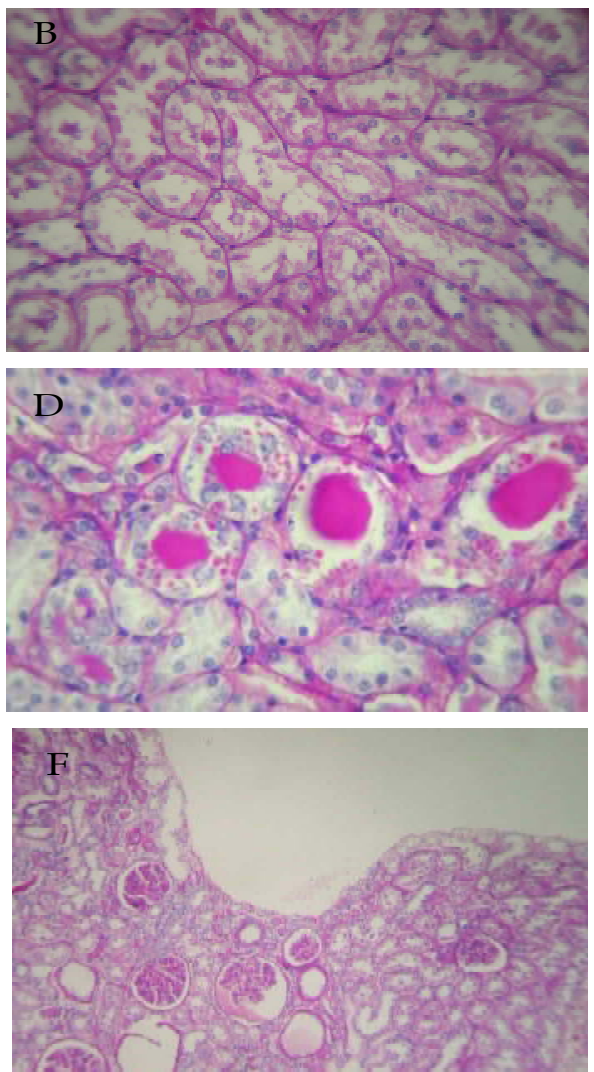

Fig. 3. (A) Intense lymphocytic infiltrate in renal pelvis (18-month-old eSMT female) (40X); (B) Mild tubular lesions (12-month-old eSS female) (300X); (C) Moderate tubular lesions characterized by disgregation of epithelial cells (6-month-old eSMT male) (300X); (D) Group of mildly dilated tubules with lumina containing protein casts (12-month-old eSS male) (300X). (E) Panoramic view of the renal medulla showing different tubular alterations, marked dilatation with protein content (15-month-old eSMT male) (100X); (F) Area of subcapsular retraction due to fibrosis. Parenchymal atrophy and lymphocytic infiltrates (24month-old eSS male) (40X). HE and Periodic acid-Schiff (PAS) stain. 
Areas of arteriolar hyalinosis and thickening of smooth muscle were observed in eSMT males from 9 months, in eSS males and eSMT females from 12 months and in eSS females from 21 month-old.

A few focal interstitial and pyelic mononuclear cell aggregates (Fig $3 \mathrm{~A}$ ), concomitant with a mild tubular disruption, were apparent in 6-month-old eSS and eSMT males (Fig 3 B and $3 \mathrm{C})$. Groups of atrophic tubules with their lumina filled by hyaline casts were already noticeable in some 6-month-old eSS and eSMT males, progressing with ageing (Fig $3 \mathrm{D}$ and 3 E). Prominent interstitial fibrosis and tubular atrophy and dilatation with vacuolization and desquamation of tubular cells, were observed in 100\% of eSS and eSMT males at 18-24 months of age and older; these features were also detected in some 12-month-old eSS and eSMT females, affecting $80 \%$ of 24 -month-old individuals. In older animals, subcapsular chronic inflammatory infiltrates, tubular atrophy and fibrosis lead to navel-like retractions of the kidney surface (Fig $3 \mathrm{~F}$ ).

Renal damage, characterized by diffuse glomerulosclerosis and conspicuous tubular nephrosis, was registered in older eSMT and eSS males. Young eSS females showed the less severe kidney injury.

No changes were observed in glomerular, tubular or interstitial structures of Wistar controls.

\section{Discussion and conclusions}

Most animal models develop mild renal lesions in early phase diabetes, but not advanced lesions in late phase and even in the best diabetic models, aging is a critical feature in the development of lesions typical of the human DN (Nakagawa, 2009). The relative long-lifespan of the eSS and eSMT rats, exceeding their metabolic disturbances, allowed the development of many of the characteristic lesions of diabetic nephropathy. This way, diabetic nephropathy worsened in both lines and sexes during the second year of life. Notwithstanding, results registered in 21-month-old control Wistar males demonstrated that ageing alone was unable to induce either a diabetic syndrome or diabetic renal lesions. It would also be argued that a particularly inherited liability of eSMT line might be an important single factor leading to a more severe renal injury. If so, findings point out that diabetic nephropathy developed as the result of complex interactions between the background genome response, body weight, sex and long-standing metabolic disorders.

Obesity is a very important factor in the beginning and rate of progression of metabolic disturbances and renal chronic complications of type 2 diabetes mellitus, in humans and in experimental models (Price et al., 2002; Nangaku et al., 2005). Even thought eSMT strain is not considered an obese model, these rats are more robust than eSS and this relative overweight has been considered a key factor in the generation of their earlier and more severe hyperglycaemia, hyperlipidaemia and hyperinsulinaemia (Tarrés et al., 2000; Montenegro et al., 2005; Picena et al., 2007). It is important to remark that eSS females, with the lowest body weight, had in turn the minor phenotypic diabetic expression. eSMT females, heavier than eSS females, displayed a more severe diabetic status and showed some glomerular alterations, as reduction in glomerulus's diameter, similar to those found in eSS males.

The degree and duration of hyperglycaemia constitute relevant risk factors regarding the occurrence and severity of renal impairment in people with both Type 1 (Alaveras et al., 1997) and Type 2 Diabetes Mellitus (Ohkubo et al., 1995) as well as in induced diabetic 
animal models (Kern \& Engelman, 1990; Petersen et al., 1988). This way, the greater glucose metabolic disorder in eSS and eSMT males was clearly part of their more severe renal lesions. Several studies have pointed toward an association between sex hormones and the risk of Type 2 Diabetes Mellitus in men and women (Ding et al., 2006). A study in the OLETF rats provided a strong support for this idea by showing that the incidence of Type 2 Diabetes Mellitus was $100 \%$ in males and $0 \%$ in females (Shi et al., 1994). The higher incidence and severity of nephropathy in Type 2 diabetic male patients and the opposite in women indicate that sex hormones impact in the development and progression of diabetic renal disease by mechanisms yet poorly understood (Maric, 2009). The influence of sex hormones over the eSS diabetic syndrome was studied in rats gonadectomized at 90 days of age (Tarrés et al., 1997). Spayed animals showed higher body weight, early and impaired intolerance to glucose and a decreased number of large pancreatic islets. Despite their lower biomass, castrated males did not evidence impairment in their intolerance to glucose, changes in insulinemia or remarkable modifications in endocrine pancreas histology. Further studies are needed for elucidating the complex interactions between genotype, body weight and sex in the onset of diabetes and the severity of chronic complications in the eSS and eSMT lines.

Transforming growth factor-beta 1 (TGF-beta1) appears to be an important downstream mediator for the development of renal hypertrophy and the accumulation of mesangial extracellular matrix components (Ziyadeh \& Wolf, 2008). In the OLETF rats, plasma TGFbeta 1 and vascular TGF-beta type II receptors exist to a greater extent in pre- and early stages of diabetes mellitus when compared with non diabetic rats (Hosomi et al., 2002). Streptozotocin-induced type 2 diabetic rats fed a high fat diet developed a higher proportion of sclerosed glomeruli than type 1 diabetic rats and the expression of CTGF and TGF-beta was significantly increased, despite their lower blood glucose levels and proteinuria (Danda et al., 2005). The connective tissue growth factor (CTGF) is also overexpressed and involving in the pathogenesis of diabetic nephropathy; results from type 2 diabetic ob/ob mice demonstrated that albuminuria strongly correlated with urinary CTGF excretion (Roestenberg et al., 2006). The activated renin-angiotensin system (RAS) has been implicated in the acceleration of diabetic renal disease in type 2 diabetic OLETF rats, as indicated by the long-lasting renoprotective effects of temporary angiotensin II blockage during the prediabetic stage, independent of its effects on glucose metabolism (Nagai et al., 2005). The observation that in the ZDF obese rats reactive oxygen species-associated angiotensinogen enhancement plays an important role in renal damage suggests that reactive oxygen species are partly involved in intrarenal angiotensinogen augmentation, leading to the development of diabetic nephropathy (Kobori et al., 2007).

In summary, mechanisms underlying the development of diabetic nephropathy are extremely complex persisting unclear the nature of the relationship between diabetes and late-onset renal disease. Remain to be clarified whether genetic and environmental factors determining early stages of these disorders are independent from those controlling their progression (Brosius et al. 2009; Nobrega, 2009).

The morphological changes in glomeruli of both strains were characterized by basement membrane thickening and diffuse mesangial expansion and, particularly in older eSMT males, by a diffuse or segmental glomerular sclerosis, being exceptional the nodular sclerosis of Kimmelstiel-Wilson. Moreover, it also shows that, even when the principal lesions affected the glomeruli according to the severity of glomerulopathy, the disease extended to the tubulointerstitial compartment. That morphological pattern has been 
observed in Type 1 diabetic patients (Najafian et al., 2003) and in poorly controlled longterm Type 2 Diabetes Mellitus, ascribed in the Category II of Fioretto et al.'s classification (2008). However, they also suffered from retinopathy, a nonexistent complication in eSS and eSMT rats.

In congruence with Tervaert et al. (2010), most of eSS and eSMT animals less than 12-monthold could be classified in Class I (barely evident mesangial lesions) whilst rats exceeding 12 months of age could belong to Class II (diffuse mesangial glomerulosclerosis with moderate to severe expansion of mesangium). It is noteworthy to outline that although the naturally slower progress of the metabolic derangement in eSS males with respect to the eSMT, almost all males over 18 months of age in both lines could be classified as Class IV (advanced glomerulosclerosis). Even though, lesions compatible with Class III (nodular sclerosis or presence of one Kimmelstiel-Wilson nodule at least) were detected in only one 18-month-old eSMT male rat. This single finding makes it exceptional and fits with other spontaneous diabetic murine models (Yuzawa et al., 2008).

It has been reported that nodular glomerulosclerosis is present in diabetic patients with more progressed clinical and pathological features (Jang \& Park, 2009). Nevertheless, other authors have sustained that diffuse and nodular sclerosis could be two discrete patterns of glomerulopathy caused by different pathophysiological mechanisms as Kimmelstiel-Wilson lesion correlates with diabetic retinopathy but most of Type 2 diabetic patients without retinopathy develop diffuse mesangial sclerosis (Schwartz et al., 1998). Interestingly, no lesions of retinopathy have ever been detected in either eSS or in eSMT rats (Tarrés et al., 1990; Tarrés et al., 2000; Picena et al., 2005). Moreover, although retinopathy and microalbuminuria are positively associated in Type 1 diabetic patients, the substantial discordances between glomerulopathy and retinopathy reported in Type 2 Diabetes Mellitus (Kanauchi et al., 1998; Boelter et al., 2006) highlights that kidney and retina are distinct organs with diverse underlying pathophysiologic mechanisms (Blum et al., 2011). Further studies on the eSS and eSMT lines rats could be useful for studying the aforesaid differences.

Renal enlargement, particularly perceptible in eSMT males via the increase in kidney weights and diffuse mesangial expansion, evokes early stages of diabetic nephropathy. Notwithstanding, the areas of tubular atrophy detected in some eSS and particularly in the eSMT males at $\sim 6$ month, suggest a more advanced phase of diabetic nephropathy. Moreover, progression to macroalbuminuria and uremia already demonstrated in eSS male rats from 6 to 12 months of age in eSS males (Daniele et al., 2000), may be correlated with the increasing loss of glomerular filtration rate accompanying each nephron sclerosis during the progression of diabetic nephropathy. While hyperglycaemia-induced osmotic polyuria has been implied as a relevant role in the onset and evolution of tubulointerstitial injury by causing an early tubular cell injury in the dilated collecting ducts (Wang et al., 2008), careful attention should be paid in the persistent glycosuria detected in eSS and eSMT rats (Martínez et al., 1988, Montenegro et al., 2005). Moreover, the differences found between diabetic rats and Wistar controls as well as between both diabetic lines in superficial and juxtamedullary glomeruli glucidic residues and in convoluted proximal tubules ones could be indicative of alterations in the filtration and in the intracellular tubular processes (Frontini et al., 2008).

As suggested by Murata et al., 2002 in the Otsuka Long-Evans Tokushima Fatty (OLEFT) rats, we guess that the phenomenon of apoptosis could be operating at glomerular level in eSS and eSMT males which displayed a noticeable and increasing number of smaller 
glomeruli as they get older. Furthermore, apoptosis induced by chronic hyperglycaemia has been related by Picena et al, (2007) with the dramatic reduction of the area of the islets of Langerhans described in older eSS males by Gomez Dumm et al., (1989). In diabetic nephropathy, the degree of proteinuria correlates with the progression of glomerulosclerosis and tubulointerstitial fibrosis (Wolf \& Ziyadeh, 2007). The early albuminuria from 24-hs collections, the loss of glomerular filtration rate in 6-month-old eSS males and the progression to macroalbuminuria and uremia from 6 to 12 months of age (Daniele et al., 2000), could be due to an increasing number of glomeruli affected associated to the progressive worsening of glucose and lipid disorders, particularly the rising values of hyperglycaemia, triglycerides, non-esterified fatty acids, total cholesterol, and low-density lipoprotein cholesterol with high- density lipoprotein-cholesterol reduced, demonstrated in this strain at 12 month of age (Daniele et al., 2010). Previous studies in humans and animals have also suggested that altered lipid metabolism causes glomerular injury and promotes deterioration of glomerular function (Diamond \& Karnovsky, 1987; Kasiske et al., 1988; Maric et al., 2004).

In humans, oxidative stress is linked to multiple chronic diabetic complications (Giacco \& Brownlee, 2010). It is increasingly evident that changes in cellular function resulting in oxidative stress play a key role in the development and progression of diabetic nephropathy (Forbes et al., 2008). Moreover, oxidized low density lipoprotein particles and non-esterified fatty acids could damage the mesangial cells and the tubulointerstitial tissue through different pathogenetic mechanisms (Nosadini \& Tonolo, 2011). Interestingly, in 12 monthold eSS rats increased basal glycaemia and fructosamine values correlate with those of lipid peroxidation substances and inversely with total antioxidant capacity (Daniele et al., 2007). In agreement with the data in diabetic patients and in other experimental diabetic models, and taking into account that hyperlipidaemia and oxidative stress have been syndicated as having major roles in the pathogenesis of the diabetic nephropathy (Kume et al., 2008), we suggest that early hyperinsulinemia and lipid disorders, already demonstrated in eSS rats (Montanaro et al., 2003. Daniele et al., 2010) and in eSMT rats (Tarrés MC et al., 2000) as well as the oxidative stress previously verified in eSS male rats (Daniele et al., 2007), are key players in the development of the diabetic nephropathy in eSS and eSMT rats. Though new experiments could be undertaken in eSS and eSMT rats to brighten the genesis and evolution of their nephropathy, we conclude that these two spontaneously diabetic rats closely resemble the advanced human diabetic nephropathy and, simultaneously, have opened valuable opportunities for enhance our understanding about the interactions between glucose and lipid disorders and the pathways towards diabetic nephropathy, a relevant cause of morbidity and mortality in the diabetic population and the leading cause of end-stage renal failure in the Western World.

\section{Acknowledgments}

The authors are grateful to the School of Medicine, National University of Rosario, for financial support and to Wiener Laboratories for the their invaluable contribution of commercial kits

\section{References}

Alaveras, AE; Thomas, SM; Sagriotis, A et al. (1997). Diabetic Nephropathy: Diagnosis, Prevention, and Treatment: Evaluation of Patients With Diabetic Nephropathy. Nephrol Dial transplant 12, Suppl. 2, 71-74, ISSN 0931-0509 
American Diabetic Association (ADA) (2009). Diagnosis and Classification of Diabetes Mellitus. Diabetes Care 32, Suppl.1, S62-S67, ISSN 0149-5992

Blum, M; Saemann, A \& Wolf, G (2011). The eye, the kidney and microcirculation Editorial Comments. Nephrol Dial Transplant 26, 1, 4-6, ISSN 0931-0509

Boelter, MC; Gross; JL; Canani LH et al. (2006). Proliferative diabetic nephropathy with microalbuminuria in patients with type 2 diabetes. Braz J Med Biol Res 39, 8, 1033-1039, ISSN 0100-879X

Breyer, MD; Bottinger, EP; Brosius, FC et al. (2005). Mouse models of diabetic nephropathy. J Am Soc Nephrol 16, 1, 27-45, ISSN 1046-6673

Brosius, FC; Alpers, CE; Bottinger, EP et al. (2009) Mouse models of diabetic nephropathy. J Am Soc Nephrol 20, 12, 2503-2512, ISSN 1046-6673

Caballero, AE \& Tenzer, P (2007). Building cultural competency for improved diabetes care: Latino Americans and diabetes. J Fam Pract 56, 9, S29-S37, ISSN 0094-3509

Calderari, SA; Gonzalez, AC \& Gayol, MD (1987). Spontaneous hypertriglyceridemic obesity and hyperglycaemia in an inbred line of rats. Int J Obes 11, 6, 571-579, ISSN 03070565

Calderari, SA; Font, MT; Garrocq, O et al. (1991). The inbred IIM/Fm stock. Rat News Let 25, 1, 28-29. ISSN 0309-1848

Chatzigeorgiou, A; Halapas, A; Kalafatakis, K et al. (2009). The use of animal models in the study of diabetes mellitus. In Vivo 23, 2, 245-258, ISSN 0258-851X

Danda, RS; Habiba, NM; Rincon-Choles, H; Bhandari, BK et al. (2005). Kidney involvement in a nongenetic rat model of type 2 diabetes. Kidney International 68, 6, 2562-2571 ISSN 0085-2538

Daniele, S; Arriaga, S; Martínez, SM et al. (2000). Onset and evolution of nephropathy in rats with spontaneous diabetes mellitus. J Physiol Biochem 56, 1, 45-54, ISSN 1138-7548

Daniele, SM; Picena, JC; Montenegro, SM et al. (2007). Hígado graso no alcohólico en ratas machos de una línea con diabetes genética. Electron J Biomed 7, 3, 29-39, ISSN 1697090X

Daniele, SM; Montenegro, SM; Tarrés, MC et al. (2010). The eSS rat, a nonobese model of disordered glucose and lipid metabolism and fatty liver. Diabetol Metabol Syndr 2, 3 , 1-5, ISSN 1758-5996

Diamond, J \& Karnovsky, M. (1987) Exacerbation of chronic aminonucleoside nephrosis by dietary cholesterol supplementation. Kidney Int 32, 5, 671-678, ISSN 0085-2538

Ding, EL; Song, Y; Malik, VS et al. (2006). Sex differences of endogenous sex hormones and risk of type 2 diabetes: a systematic review and metaanalysis. JAMA 295, 11, 12881299, ISSN 0098748

Dronavalli, S \& Barkis GL (2008). Mechanistic Insights into Diuretic-Induced Insulin Resistance. Hypertension 52, 6, 1009-1011, ISSN 0194911X

Fioretto, P; Caramori, ML \& Mauer, M (2008). The kidney in diabetes: dynamic pathways of injury and repair. The Camillo Golgi Lecture. Diabetologia 51, 8, 1347-1355, ISSN 0012-186X

Forbes, JM; Coughlan, MT \& Cooper, ME (2008). Oxidative stress as a major culprit in kidney disease in diabetes. Diabetes 57, 6, 1446-1154, ISSN 0012-1797 
Frontini, AV; Hisano, N \& D’Ottavio, AE (2008). La densidad óptica aplicada al estudio lectinhistoquímico de radicales glucídicos néfricos en ratas diabéticas tipo 2 . Electron J Biomed 6, 1, 36-44, ISSN 1697-090X

Giacco, F \& Brownlee, M (2010). Oxidative stress and diabetic complications. Circ Res 29, 107, 1058-1070, ISSN 0009-7330

Gomez Dumm, CL; Semino, MC \& Gagliardino, JJ (1990). Sequential morphological changes in pancreatic islets of spontaneously diabetic rats. Pancreas 5, 5, 533-539, ISSN 08853177

Hisano, N; D'Ottavio, AE \& Calderari, SA (1994). Female reproductive profile in a fertile genetically obese line of rats. J Exp Zool 270, 5, 486-490, ISSN 1932-5223

Hosomi, N; Noma, T; Ohyama H \& et al. (2002). Vascular proliferation and transforming growth factor-beta expression in pre- and early stage of diabetes mellitus in Otsuka Long-Evans Tokushima fatty rats. Atherosclerosis 162, 1, 69-76 ISSN 0021-9150

Hudkins, KL; Pichaiwong, W, et al. (2010). Ob/Ob mutant mice model progressive diabetic nephropathy. J Am Soc Nephrol 21, 9, 1533-1542, ISSN 1046-6673

Jang, SH \& Park, MH (2009). The morphologic patterns of diabetic nephropathy in Koreans. Korean J Pathol 43, 1, 36-42, ISSN 1738-1843

Janssen, U; Phillips, AO \& Floege, J (1999). Rodent models of nephropathy associated with type II diabetes. J Nephrol 12, 3, 159-172, ISSN 1121-8428

Kanauchi, M; Kawano, T; Uyama H et al. (1998). Discordance between retinopathy and nephropathy in type 2 diabetes. Nephron 80, 2, 171-174, ISSN 0028-2766

Kasiske, B; Cleary, M; O'Donnell, $\mathrm{M}$ et al. (1988). Mechanisms of glomerular injury in the obese Zucker rat. Kidney Int 33, 3, 667-672, ISSN 0085-2538

Kern, TS \& Engelman, RL (1990). Arrest of glomerulopathy in diabetic dogs by improved glycaemic control. Diabetologia 33, 522-525, ISSN: 0012-186X

Kobori, H; Ozawa, Y; Suzaki, Y; Prieto-Carrasquero, MC (2006). Intratubular angiotensinogen in hypertension and kidney Diseases. Am J Hypertens 19, 5, 541550 ISSN 0895-7061

Kume, S; Uzu, T; Isshiki TK et al (2008). Peroxisome proliferator-activated receptors in diabetic nephropathy (Review Article). PPAR Res 4, 7, 1-11, ISSN 1687- 4765

Lee, G (2003). End - stage renal disease in the Asian - Pacific region Semin Nephrol 23, 1, 107114, ISSN 0270-9295

Maric, C; Sandberg, K \& Hinojosa-Laborde, C (2004). Glomerulosclerosis and tubulointerstitial fibrosis are attenuated with $17-\beta$ estradiol in the aging Dahl saltsensitive rat. J Am Soc Nephrol 15, 6, 1546-1556, ISSN 1046-6673

Maric, C (2009). Sex, diabetes and the kidneys. Am J Physiol-Renal Physiol 296, 4, F680-F688, ISSN 0363-6127

Martínez, SM; Tarrés, MC; Montenegro, SM et al (1988). Spontaneous diabetes in eSS rats. Acta diabetol lat 25, 4, 303-313, ISSN 0001-5563

Martínez, SM; Tarrés, MC; Picena, JC et al (1993). eSS rat, an animal model for the study of spontaneous non-insulin-dependent diabetes, In: Lessons from Animal Diabetes IV. E Shafrir, Ed. Smith-Gordon, 75-90, ISBN 1854630075, London, UK 
Montanaro, M; Rimoldi, OJ; Igal, RA et al. (2003). Hepatic $\Delta 9, \Delta 6$ and $\Delta 5$ Desaturations in the Non-Insulin Dependent Diabetic Mellitus eSS Rats. Lipids 38, 8, 827-832, ISSN 00244201

Montenegro, SM; Tarrés, MC; Picena, JC et al. (2005). Conducta alimentaria y perfil glucémico en dos modelos murinos de diabetes genética: eSS y eSMT. Biomédica 25, 4, 441-450, ISSN 0120-4157

Murata, I; Takemura, G; Asano, A et al. (2002). Apoptotic cell loss following cell proliferation in renal glomeruli of Otsuka Long-Evans Tokushima Fatty rats, a model of type 2 diabetes. Am J Nephrol 22, 5-6, 587-595, ISSN 0250-8095

Nagai, Y; Yao, L; Kobori, H et al., (2005). Temporary Angiotensin II blockade at the prediabetic stage attenuates the development of renal injury in Type 2 diabetic rats. J Am Soc Nephrol 16, 3, 703-711 ISSN 1046-6673

Najafian, B; Kim, Y; Crosson, JT et al. (2003). Atubular glomeruli and glomerulotubular junction abnormalities in diabetic nephopathy. J Am Soc Nephrol 14, 4, 908-917, ISSN 1046-6673

Nakagawa, T (2009). A new mouse model resembling human diabetic nephropathy: uncoupling of VEGF with eNOS as a novel pathogenic mechanism. Clin Nephrol 71, 2, 103-9, ISSN 0301-0430

Nangaku, M; Izuhara, Y; Usuda, $\mathrm{N}$ et al. (2005). In a type 2 diabetic nephropathy rat model, the improvement of obesity by a low calorie diet reduces oxidative/carbonyl stress and prevents diabetic nephropathy. Nephrol Dial. Transplant 20, 12, 2661-2669, ISSN 0931- 0509

Nobrega, MA; Solberg Woods, LS; Fleming, S; Jacob, HJ (2009). Distinct genetic regulation of progression of diabetes and renal disease in the Goto-Kakizaki rat. Physiol Genomics 39: 38-46 ISSN 1531-2267

Nosadini, R \& Tonolo, G. (2011). Role of oxidized low density lipoproteins and free fatty acids in the pathogenesis of glomerulopathy and tubulointerstitial lesions in type 2 diabetes. Nutr Metab Cardiovasc Dis 21, 2, 79-85, ISSN 0939-4753

Ohkubo, Y; Kishikawa, H; Araki, E et al. (1995). Intensive insulin therapy prevents the progression of diabetic microvascular complications in Japanese patients with noninsulin-dependent diabetes mellitus: a randomized prospective 6-year study. Diabetes Res Clin Pract 28, 2, 103-117, ISSN 0168-8227

Petersen, J; Ross, J \& Rabkin, R (1988). Effect of insulin therapy on established diabetic nephropathy in rats. Diabetes 37, 10, 1346-1350, ISSN 0012-1797

Picena, JC; Daniele, SM; Tarrés, MC et al. (2005). An animal model fits for studying divergences among diabetic microvascular complications. Electron J Biomed 3, 2, 3943, ISSN 1697-090X

Picena, JC; Montenegro, SM; Tarrés, MC et al. (2007). Modificaciones dinámicas en los islotes de Langerhans de dos líneas de ratas espontáneamente diabéticas: eSS y eSMT. Medicina (B Aires) 67, 4, 331-340, ISSN 0025-7680

Price, DA; Lansang, MC; Osey, SY et al. (2002). Type 2 diabetes, obesity and the renal response to blocking the renin system with irbesartan. Diabetic Med 19, 10, 858-861, ISSN 0742-3071 
Roestenberg, P; van Nieuwenhoven, FA; Joles, JA; Trischberger, C et al, (2006). Temporal expression profile and distribution pattern indicate a role of connective tissue growth factor (CTGF/CCN-2) in diabetic nephropathy in mice. Am J Physiol Renal Physiol 290, 6, F1344-1354 ISSN 1522-1466

Schwartz, MM; Lewis, EJ; Leonard-Martin, T et al. (1998). Renal pathology patterns in type II diabetes mellitus: relationship with retinopathy. The Collaborative Study Group. Nephrol Dial. Transplant. 13, 10, 2547-2552, ISSN 0931- 0509

Shi, K; Mizuno, A; Sano, T et al. (1994). Sexual difference in the incidence of diabetes mellitus in Otsuka-Long-Evans-Tokushima-Fatty rats: effects of castration and sex hormone replacement on its incidence. Metabolism 43, 10, 1214-1220, ISSN 0026-0495

SPSS (2006). IBM SPSS Statistics, 15.0.1 version, SPSS Inc, New York, USA

Srinivasan, K \& Ramarao, P (2007). Animal models in type 2 diabetes research: an overview. Indian J Med Res 125, 3, 451-472, ISSN 0971-5916

Stewart, JH; McCredie, MR; Williams, SM et al. (2006). The enigma of hypertensive ESRD: observations on incidence and trends in 18 European, Canadian, and Asian-Pacific populations, 1998 to 2002. Am J Kidney Dis 48, 2, 183-191, ISSN 0272-6386

Tarrés, MC; Martínez, SM; Montenegro, SM et al. (1990). Relación entre dieta, biomasa y expresión de la diabetes en la rata eSS. Medicina (Buenos Aires) 50, 3, 235-243, ISSN 0025-7680

Tarrés, MC; Martínez, SM; Montenegro, SM et al. (1992). The eSS rat: A new model of noninsulin-dependent human diabetes. Am J Pathol 141, 3, 761-763, ISSN 0002-9440

Tarrés, MC; Martínez, SM; Montenegro, SM et al. (1997). Influence of gonadectomy in eSS diabetic rats. J Physiol Biochem 53, 2, 211-216, ISSN 1138-7548

Tarrés, MC; Montenegro, S; Martínez, SM et al. (2000). The eSMT rat: a murine model of type 2 human diabetes. Chapter: Animal models in the study of human diseases, In: Animal Research and Welfare. A Partnership. Proceedings of the International Joint Meeting between 12th ICLAS General Assembly \& Conference and the 7th Felasa Symposium. Laboratory Animals Ltd., 93-94, ISBN: 0-901334-13-8. London, UK

Tervaert, TW; Mooyaart, AL; Amann, K et al. (2010) Pathologic classification of diabetic nephropathy. J Am Soc Nephrol 21, 4, 556-563, ISSN 1046-6673

Tesch, GH \& Allen, TJ (2007). Rodent models of streptozotocin-induced diabetic nephropathy. Nephrology (Carlton) 12, 3, 261-266, ISSN1320-5358

U.S Renal Data System (USRDS) (2008). Annual Data Report: Atlas of Chronic Kidney Disease and End-Stage Renal Disease in the United States, National Institutes of Health, National Institute of Diabetes and Digestive and Kidney Diseases. Bethesda, MD. 2, Précis, 29-33

U.S Renal Data System (USRDS) (2010). Annual Data Report: Atlas of Chronic Kidney Disease and End-Stage Renal Disease in the United States, National Institutes of Health, National Institute of Diabetes and Digestive and Kidney Diseases, Bethesda, MD. 2, Précis, 209-222

Villar, E \& Zaoui, P (2010). Diabetes and chronic kidney disease: Lessons from renal epidemiology. Nephrol Ther 6, 7, 585-590, ISSN 1769-7255

Wang, S; Mitu, GM \& Hirschberg, R (2008). Osmotic polyuria: an overlooked mechanism in diabetic nephropathy. Nephrol Dial Transplant 23, 7, 2167-2172, ISSN 0931- 0509 
Wolf, G \& Ziyadeh, FN (2007). Cellular and molecular mechanisms of proteinuria in diabetic nephropathy. Nephron Physiol 106, 2, 26-31, ISSN 1660-2137

Yuzawa, Y; Niki, I, Kosugi, T et al. (2008). Overexpression of Calmodulin in Pancreatic $\beta$ Cells Induces Diabetic Nephropathy. J Am Soc Nephrol 19, 9. 1701-1711, ISSN 10466673

Ziyadeh, FN \& Wolf, G (2008). Pathogenesis of the podocytopathy and proteinuria in diabetic glomerulopathy. Curr Diabetes Rev 4, 1, 39-45 ISSN 1573-3998

Zimmet, P; Alberti, KGM \& Shaw, J (2001). Global and societal implications of the diabetic epidemic. Nature 414, 12, 782-787, ISSN 0028-0836 


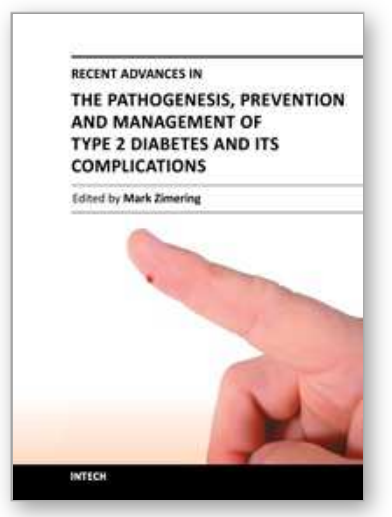

\author{
Recent Advances in the Pathogenesis, Prevention and \\ Management of Type 2 Diabetes and its Complications \\ Edited by Prof. Mark Zimering
}

ISBN 978-953-307-597-6

Hard cover, 442 pages

Publisher InTech

Published online 29, August, 2011

Published in print edition August, 2011

Type 2 diabetes â€œmellitusâ€ affects nearly 120 million persons worldwide- and according to the World Health Organization this number is expected to double by the year 2030. Owing to a rapidly increasing disease prevalence, the medical, social and economic burdens associated with the microvascular and macrovascular complications of type 2 diabetes are likely to increase dramatically in the coming decades. In this volume, leading contributors to the field review the pathogenesis, treatment and management of type 2 diabetes and its complications. They provide invaluable insight and share their discoveries about potentially important new techniques for the diagnosis, treatment and prevention of diabetic complications.

\title{
How to reference
}

In order to correctly reference this scholarly work, feel free to copy and paste the following:

Juan Carlos Picena, Silvana Marisa Montenegro, Alberto Enrique D’Ottavio, Maria Cristina Tarrés and Stella Maris Martinez (2011). A Diachronic Study of Diabetic Nephropathy in Two Autochthonous Lines of Rats to Understand Diabetic Chronic Complications, Recent Advances in the Pathogenesis, Prevention and Management of Type 2 Diabetes and its Complications, Prof. Mark Zimering (Ed.), ISBN: 978-953-307-597-6, InTech, Available from: http://www.intechopen.com/books/recent-advances-in-the-pathogenesis-preventionand-management-of-type-2-diabetes-and-its-complications/a-diachronic-study-of-diabetic-nephropathy-in-twoautochthonous-lines-of-rats-to-understand-diabetic

\section{INTECH}

open science | open minds

\section{InTech Europe}

University Campus STeP Ri

Slavka Krautzeka 83/A

51000 Rijeka, Croatia

Phone: +385 (51) 770447

Fax: +385 (51) 686166

www.intechopen.com

\section{InTech China}

Unit 405, Office Block, Hotel Equatorial Shanghai

No.65, Yan An Road (West), Shanghai, 200040, China 中国上海市延安西路65号上海国际贵都大饭店办公楼 405 单元

Phone: +86-21-62489820

Fax: $+86-21-62489821$ 
(C) 2011 The Author(s). Licensee IntechOpen. This chapter is distributed under the terms of the Creative Commons Attribution-NonCommercialShareAlike-3.0 License, which permits use, distribution and reproduction for non-commercial purposes, provided the original is properly cited and derivative works building on this content are distributed under the same license. 